\title{
Bilateral Clavicle Fracture : A Case Report
}

\section{Dr Kiran Kalaiah ${ }^{1}$, Dr Sridhar D K ${ }^{2}$, Dr Ravishankar $\mathbf{J}^{3}$, Dr Baibhav Kumar Agarwal ${ }^{4}$}

\author{
${ }^{1}$ Professor and HOD, ${ }^{2}$ Assistant Professor, ${ }^{3}$ Assistant Professor, ${ }^{4}$ Junior Resident, \\ Department of Orthopaedics, \\ Sri Siddhartha Medical College \& Research Centre, Agalakote, Tumakuru
}

DOI - 10.46319/RJMAHS.2019.v02i01.007

\section{Abstract}

Clavicle is a frequently fractured bone in the body. It accounts for $44 \%$ of all fractures around the shoulder girdle and $2.6 \%$ of all fractures. Bilateral clavicle fracture is rare with incidence of $0.48 \%$ of all clavicle fracture. Undisplaced and minimally displaced fractures are mostly managed conservatively. Displaced fractures are treated operatively which improves the functional outcome and lowers the rate of malunion and non-union. A 45 years old male met with a road traffic accident and was brought to our emergency department. He was diagnosed to have bilateral displaced midshaft fracture of clavicle. Fracture was classified as Allman Group 1, Robinson type 2B1 bilaterally. Both fractures were fixed with precontoured clavicle locking plate by classical superior incision in two different sitting 1 week apart. Treating bilateral clavicle fracture with locking compression plates is a safe and effective method. It helps in early pain relief, rapid recovery, good functional outcome and decreases the period of morbidity.

Keywords: Bilateral, Clavicle, Plating

\section{Introduction}

Clavicle is a frequently fractured bone in the body. It accounts for $44 \%$ of all fractures around the shoulder girdle and $2.6 \%$ of all fractures. ${ }^{[1]}$ Bilateral clavicle fracture is rare with incidence of $0.48 \%$ of all clavicle fractures. ${ }^{[2]}$ Mode of injury in majority of the cases is high velocity trauma. Mechanism of injury includes bilateral direct blow to the shoulder girdle or compressive force across both the shoulder girdles. ${ }^{[2,3]}$ Most common site for a fracture is midshaft (69-82\%) followed by lateral end (21-28\%) and medial end $(2-3 \%) .{ }^{[4]}$ Undisplaced and minimally displaced fractures are mostly managed conservatively. Displaced fractures are treated operatively which improves the functional outcome and lowers the rate of malunion and non-union. ${ }^{[5]}$ Fracture clavicle was treated conservatively in the past. But over the years operative treatment for clavicle fractures has become popular with the help of locking compression plates.

\section{Case report}

A male patient aged around 45 years was brought to Sri Siddhartha Medical College and hospital emergency department on 20-09-2018. He met with a road traffic accident where his shoulders got compressed between the ground and the vehicle. He was presented to us with the history of bilateral shoulder pain. On examination, fracture on his right and left midclavicular region was visible as abnormal bony protuberance. $\mathrm{X}$-ray revealed bilateral displaced midshaft fracture of clavicles. Fracture was classified as Allman Group 1, Robinson type 2B1 bilaterally.

Both upper limbs were provisionally immobilized in sling and for mobilization purpose due to displacement of both the fractures open reduction and locking plate fixation was planned. Subsequently all the routine investigations were done as per the hospital protocol and patient was operated two days later. Both fractures were fixed with precontoured clavicle locking plate by classical superior incision in two different sittings, one

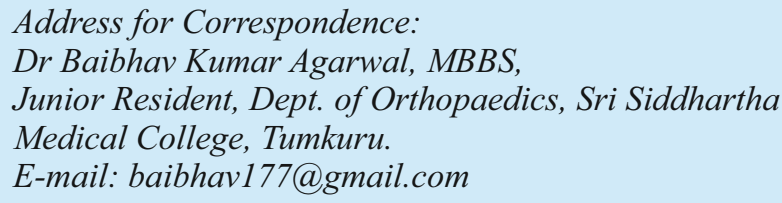


week apart.

Both intraoperative and postoperative periods were uneventful. Arm sling pouch was applied for three weeks post-operatively. Stitches were removed on $12^{\text {th }}$ post-operative day and pendulum exercises were started 1 month post operatively. Patient was followed up monthly for 3 months. Six weeks following surgery both the fractures achieved good healing. No complications noted during follow up. Patient had good range of movements.

\section{Discussion}

All fractures should be immobilized as per the general orthopaedic principles. This prevents delayed union and non-union, which can result due to movement at fracture site. Pain, swelling and discomfort are initial symptoms for any fractures. These symptoms are even more with bilateral clavicle fractures and leave the patient incapacitated. Immobilization for longer duration can cause stiffness of the shoulder joint and secondary osteoarthritis of the acromioclavicular joint.

Anatomically pre contoured locking compression plate is an excellent option for treating patients with fracture clavicle. It gives a stable fixation even in elderly patients with osteoporotic bone.$^{[6]}$ The functional outcome of the shoulder can be improved by treating clavicle fractures with early surgical intervention. ${ }^{[7]}$

Clavicle fractures can be associated with complex disruption of the shoulder girdle, by stabilizing the clavicle fracture, the shoulder girdle complex can also be stabilized. ${ }^{[8]}$ Unilateral clavicle fractures can be managed conservatively and are operated only when indicated. Bilateral clavicle fractures per se are an indication for surgical fixation.

Pre contoured locking compression plates are becoming popular for treatment of various fractures. The weight of the arm creates a force which can increase the chances of screw back out, especially on the lateral aspect. The use of conventional non locking plates has higher incidence of implant failure, more so in the elderly patients with osteoporotic bones. Complications like screw back out can be improved and prevented with the help of locking plates. $^{[9,10]}$.

Fractures around the articular surface which requires early mobilization are now being treated with precontoured angle specific locking plates ${ }^{[11]}$ With surgical fixation patient can be allowed for early non

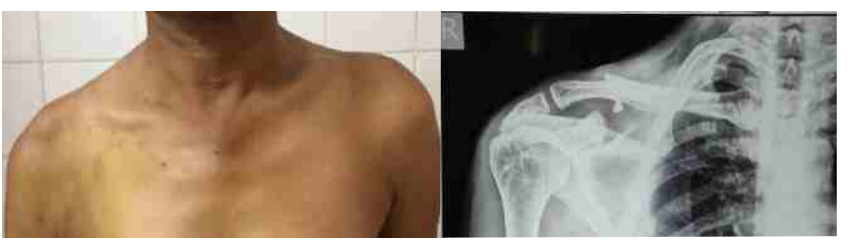

Figure 1. Clinical Picture Figure 2. Preoperative X-Ray Right Clavicle AP View

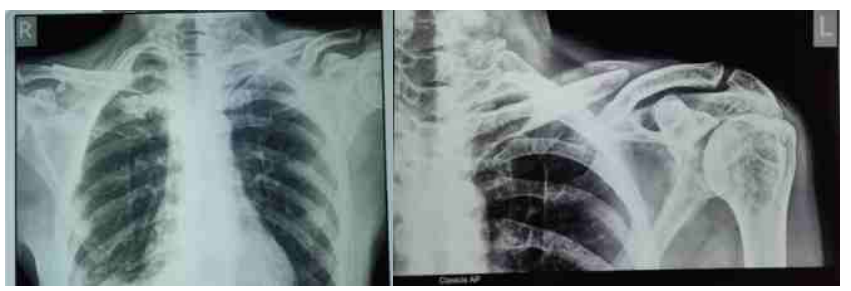

Figure 3. Chest X-RAY PA view

Figure 4. Preoperative X-RAY left clavicle AP view

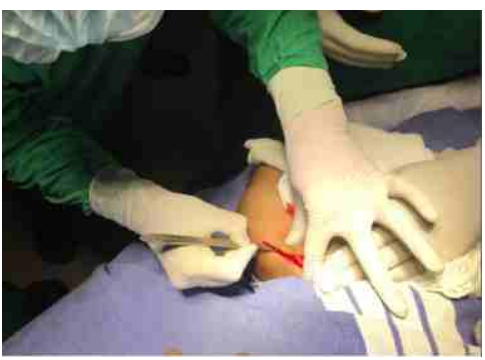

Figure 5. Superior incision

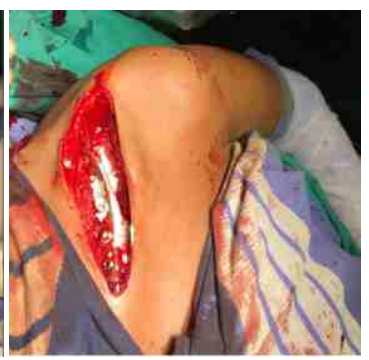

Figure 6. After fixation with LCP

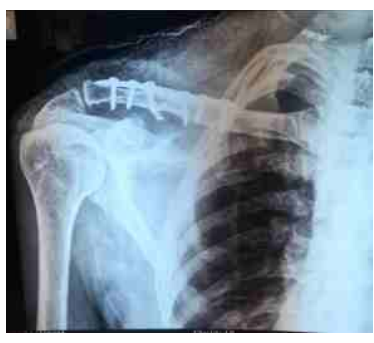

Figure 7. Postoperative Figure 8. Postoperative X-ray left $\mathrm{X}$-ray right clavicle

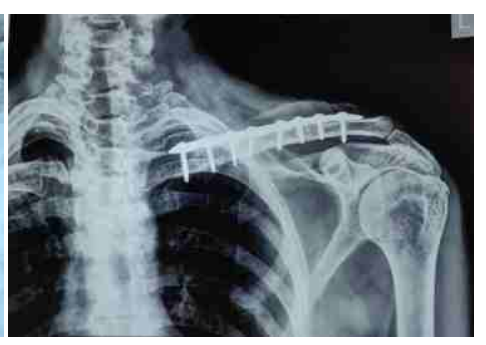

clavicle weight bearing activities including activities of daily living. Currently available locking plates are pre contoured according to the shape of clavicle thus eliminating the need to bend the plates. This prevents implant failure and increases the longevity of the implant in-situ.

\section{Conclusion}

Treating bilateral clavicle fracture with locking compression plates is a safe and effective method. It helps in early pain relief, rapid recovery, good functional outcome and decreases the period of morbidity. 


\section{Financial Support and sponsorship: Nil}

\section{Conflicts of interest: Nil}

\section{References}

1. Postacchini F1, Gumina S, De Santis P, Albo FJ. Epidemiology of clavicle fractures. Shoulder Elbow Surg. 2002; 11(5):452-6.

2. CH Snyckers MB ChB, Dip. PEC (SA), MMed (Orth), FCSA (Orth) Consultant, Bilateral clavicle fractures. A case report and review of the literature. HET van den Bout MBChB, LLB Senior Registrar, Department of Orthopaedics, University of Pretoria Department of Orthopaedics, University of Pretoria; Page 56 / SA Orthopaedic journal winter. 2011; 10:2

3. Sutherland AG, Knight DJ. Bilateral fractured claviclesa pair of cases. Acta Orthop Belg. 2000; 66(3):306-307.

4. Apley AG. Solomon L. Injuries of the shoulder and Upper arm In. Blom A. Warwick D. Michael R. Whitehouse eds. Apley \& Solomon system of orthopaedics and Trauma 10thedn. Boca Raton: CRC Press; 2018.p755-756

5. Azar FM. Beaty JH. Canale ST. Fractures of the
Shoulder, Arm, and Forearm In: Daugherty K. Jones L. eds. Campbell's operative orthopaedics $13^{\text {th }}$ edn. Philadelphia: Elsevier; 2017. p2927-2928

6. van den Bout HET. Bilateral clavicle fractures A case report and review of the literature. South Afr Orthop J. 2011; 10(2): 55-66.

7. Bajuri MY, Maidin S, Rauf A, Baharuddin M, Harjeet S. Functional outcomes of conservatively treated clavicle fractures. Clinics (Sao Paulo). 2011; 66(4): 635-9.

8. Goss TP. Double disruptions of the superior shoulder suspensory complex. Journal of Orthopaedic Trauma, 1993; 7(2):99-106.

9. Egol KA, Kubiak EN, Fulkerson E, Kummer FJ, Koval KJ Biomechanics of locked plates and screws. Journal of Orthopaedic Trauma, September 2004; 18(8):488-93.

10. Perren SM. Evolution of the internal fixation of long bone fractures. The scientific basis of biological internal fixation: choosing a new balance between stability and biology. JBJS Br. 2002;84-B: 1093-110.

11. Smith WR, Ziran BH, Anglen JO, Stahel PF. Locking plates: tips and tricks. JBJS Am. 2007;89-A (10):2298307. 